\title{
POLÍTICAS PÚBLICAS INTERSETORIAIS PARA CIDADES SUSTENTÁVEIS: A ARTICULAÇÃO ENTRE POLÍTICA URBANA E SANEAMENTO BÁSICO
}

\section{RESUMO}

\section{Daniel Machado Gomes* Nicholas Arena Paliologo**}

O objetivo do presente artigo é analisar, a partir da perspectiva das políticas públicas intersetoriais, o impacto e a relevância do saneamento básico no desenvolvimento urbano. Para isso, a metodologia utilizada combinou a revisão bibliográfica com análise de dados a fim de compreender a relação saneamento e política urbana. Os resultados alcançados revelam a necessidade de políticas públicas articuladas a fim de promover o desenvolvimento urbano de forma sustentável.

PALAVRAS-CHAVE: saneamento básico, política urbana; sustentabilidade; intersetorialidade; cidades

\section{INTERSECTORAL PUBLIC POLICIES FOR SUSTAINABLE CITIES: THE LINKS BETWEEN URBAN POLICY AND BASIC SANITATION}

\section{ABSTRACT}

The goal of this article is to analyze, from the perspective of the intersectoral public policies, impact and relevance of the basic sanitation into urban development. To this end, the methodology used combined review with data analysis in order to understand the relation sanitation and urban policy. The results reveal the need to articulate public policies in order to promote sustainable urban development.

KEYWORDS: basic sanitation, urban policy; sustainability; intersectoriality; cities.

\section{INTRODUÇÃO}

A adoção de políticas públicas intersetoriais no Brasil sempre representou, para a Administração Pública e para sociedade, um desafio difícil de ser superado. Esse desafio torna-se ainda mais complexo quando analisado a necessidade de articulação de diferentes órgãos públicos e saberes distintos que decorre da relação existente entre política urbana e saneamento.

O saneamento básico é reconhecido como fundamental para o resgate da dignidade humana e está diretamente relacionado ao desenvolvimento urbano e sustentável de um país. Isso significa que as cidades brasileiras só poderão combater as desigualdades sociais a partir

\footnotetext{
* Doutor em Filosofia pelo IFCS. Mestre em Ciências Jurídico-Civilísticas pela Universidade de Coimbra. Professor do Programa de Pós-Graduação e da Graduação em Direito da UCP. Professor da FACHA. E-mail: daniel.machado@ucp.edu.br

** Mestrando do Programa de Pós-Graduação em Direito da Universidade Federal do Estado do Rio de Janeiro UniRio. E-mail: nick.paliologo@ gmail.com

Revista de Direito Urbanístico, Cidade e Alteridade | e-ISSN: 2525-989X | Salvador | v. 4 | n. 1 | p. 80 - 94 | 
do correto investimento nas quatro vertentes do setor: abastecimento de água, esgotamento sanitário, manejo dos resíduos sólidos e drenagem urbana.

O desenvolvimento urbano pode ser compreendido como o aperfeiçoamento das condições materiais e subjetivas de vida nas cidades, com diminuição da desigualdade social e econômica. Os impactos causados pelo crescimento urbano afetam intimamente os serviços de saneamento básico. Quanto maior a população, mais intenso será o consumo de água, a geração de lixo e o acúmulo de poluição. Por isso, o grande desafio é alcançar eficiência nos serviços de saneamento, buscando a preservação ambiental e promoção de um espaço urbano saudável. Nesse sentido, o objetivo do artigo é analisar, a partir da perspectiva das políticas públicas intersetoriais, o impacto e a relevância do saneamento básico no desenvolvimento urbano.

Para isso, o presente trabalho traça uma linha de raciocínio que se inicia na revisão bibliográfica da intersetorialidade das políticas públicas, da relação entre desenvolvimento urbano, cidades sustentáveis e o direito à cidade. Em seguida, é analisado a constituição do saneamento básico como um direito e sua posição de elemento do direito à cidade.

Na parte final, é realizada a descrição dos dois principais serviços que integram o saneamento básico no Brasil: abastecimento de água e esgotamento sanitário. Para então, analisar o impacto desses no desenvolvimento urbano.

\section{1) POLÍTICAS PÚBLICAS INTERSETORIAIS}

Segundo Sueli do Nascimento (2010, p. 95), a intersetorialidade das políticas públicas passou a ser uma dimensão valorizada à medida que não se observava a eficiência, a efetividade e a eficácia esperadas na implementação das políticas setoriais, principalmente, no que se refere ao atendimento das demandas da população e aos recursos disponibilizados para a execução das mesmas. Assim, a intersetorialidade passou a ser um dos requisitos para a implementação das políticas setoriais, almejando sua efetividade por meio da articulação entre instituições governamentais e entre essas e a sociedade.

Os princípios básicos da intersetorialidade, para Garajau (2013, p. 05), são o senso de responsabilidade, de compartilhamento, parceria, envolvimento, articulação, cooperativismo, interface, conexão, participação, diálogo, trabalho em rede e integração, tendo como 
pressuposto o planejamento integrado e articulado, bem como a integração de agendas setoriais distintas.

De acordo com Sposati (2006, p.137), o princípio central é o da convergência, que é um conjunto de impulsos para a ação em determinada situação, seja ela um objeto, um tema, uma necessidade, um território, um grupo, um objetivo, uma perspectiva. Apesar disso, é necessário que a intersetorialidade sempre seja corretiva de irracionalidades entre pessoal, funções ou gastos sobrepostos, pois é um mecanismo racionalizador da ação porque é uma estratégia de gestão institucional que busca trazer mais qualidade por permitir ultrapassar limites que ocorreriam na abordagem somente setorial.

Em relação à definição, para Inojosa (2001, p.04), a intersetorialidade pode ser definida como a articulação entre saberes e experiências distintas para o planejamento, a realização de avaliação de políticas, programas e projetos, com o objetivo de atingir resultados cooperativos em situações de complexidade.

Já Sposati (2006, p.140) aponta para a criação e reconhecimento de saberes resultantes da integração entre áreas setoriais, sendo um caminho ou processo estruturador da construção de novas respostas ou novas demandas para cada uma das políticas públicas. Por outro lado, Azevedo (2003, p.41) define como a inter-relação entre as diversas políticas. Neste contexto, destaca a dificuldade para a intersetorialidade no que se refere à crescente especialização do poder público e a tendência de maximização do desempenho de cada um dos órgãos do setor estatal.

A ação intersetorial importa na articulação de saberes técnicos, uma vez que os especialistas em determinada área passam a integrar agendas coletivas e compartilhar objetivos comuns. Neste cenário, há ganhos para a população, para a organização logística das ações definidas, bem como para a organização das políticas públicas centradas em determinados territórios (NASCIMENTO, 2010, p.95).

$\mathrm{Na}$ perspectiva dos defensores das políticas intersetoriais, as políticas setoriais precisariam ser urgentemente superadas, considerando que estas estariam associadas a ações ineficientes e ineficazes. Além disso, as políticas setoriais: (a) compartilhariam de uma visão fragmentada da realidade social e, portanto, não seriam capazes de visualizar pessoas e grupos enquanto totalidades; (b) essa visão fragmentada da realidade social, por sua vez, promoveria a fragmentação e desarticulação das políticas, dificultando o atendimento às demandas da 
população; (c) poderiam levar o governo a acionar diferentes setores para o atendimento de segmentos da população idênticos, por meio de programas sociais diferentes, desperdiçando recursos públicos; (d) por corresponderem a estruturas hierarquizantes, despartamentalizadas e burocratizadas, dificultariam o trabalho coletivo, participação e controle social (BARBIERI, NOMA, 2017, p.141).

A ideia da intersetorialidade não implica na negação das características específicas de cada setor. A ideia seria somar forças para obtenção de melhores resultados. Garajau (2013, p.03) diz que o fato de tomar a interdisciplinaridade como parâmetro no bojo da política pública não significa acabar com as estruturas setorializadas, e sim obter meios de articulação entre elas com o intuito de obter resultados sinérgicos, visando à integração dos componentes específicos para a construção de um conhecimento comum.

No que toca à construção de processos intersetoriais, Inojosa (2001, p.105) elege dois elementos fundamentais: o enfoque, com recorte regional, em parcelas, programas e projetos intersetoriais; e a questão de resultados e impactos. A partir destes dois elementos, a autora (idem) discuti quatro aspectos essenciais. O primeiro aspecto se refere à mudança de paradigma que consiste em acolher uma nova maneira de pensar, com foco na complexidade e na comunicação, de forma semelhante à abordagem realizada acerca da interdisciplinariedade. O segundo aspecto concerne à adoção de um projeto político transformador para as políticas públicas, pautado pela ideia de desenvolvimento social. O terceiro aspecto é relacionado ao planejamento e avaliação participativos com base regional, que devem determinar o orçamento do Estado. Assim, a estrutura organizacional modelada pela lógica intersetorial supõe o alargamento de mecanismos de participação. Por último, está a atuação em rede de compromisso social, que consiste na atuação articulada entre Estado e sociedade.

Outro elemento associado à intersetorialidade é a descentralização. Junqueira, Inojosa e Komatsu (1997, p.24) consideram a aproximação destes conceitos importantes, na medida em que a descentralização tem a capacidade de distribuir poder para instâncias mais acessíveis a população e a intersetorialidade permite a realização do atendimento das necessidades da população de forma integrada. Estes dois conceitos voltados para o desenvolvimento social constituem um novo vetor para a modelagem da gestão pública. Para estes autores (idem), os municípios são espaços privilegiados da ação intersetorial. Nesta lógica, considera-se que é no município que se concretizará ação e integração intersetorial, por ser espaço definido social e territorialmente. 


\section{2) DIREITO À CIDADE, DESENVOLVIMENTO URBANO E CIDADES SUSTENTÁVEIS.}

É indiscutível que se vive em mundo urbanizado. Estudos divulgados pelo Organização das Nações Unidas (ONU) apontam que mais da metade da população mundial vive em cidades. No Brasil, segundo dados do Instituto Brasileiro de Geografia e Estatística (IBGE), a taxa de urbanização atingiu aproximadamente $85 \%$. Contudo, o processo de urbanização é marcado constantemente pela informalidade do espaço urbano, desigualdades e segregações socioterritoriais.

Diante desse cenário, ganha destaque o conceito de direito à cidade cunhado pelo autor francês Henri Lefebvre. Para o referido autor, o direito à cidade tem duas importantes dimensões: uma participativa e outra referente ao acesso a bens e serviços urbanos. $\mathrm{Na}$ primeira dimensão, ganha destaque a gestão democrática das cidades, a cidadania e o controle social, ou seja, a participação efetiva dos habitantes da cidade na produção do espaço urbano, a capacidade de todo cidadão poder interferir nas decisões sobre a cidade, desde seu planejamento e orçamento, até decisões sobre intervenções urbanas concretas. Pela segunda dimensão, há uma preocupação com o acesso e justa distribuição e apropriação de bens e serviços urbanos, sejam materiais ou imateriais, ou seja, de que todos aqueles que vivem na cidade sejam beneficiários do que está sendo construído, direito de acesso à cidade por todos que nela vivem (infraestrutura, mobilidade, moradia, cultura, informação e produção de conhecimento) (MORETTI, J; MORETTI, R, 2014, p. 63).

Tal entendimento é ensejado pelos estudos de David Harvey, Mark Purcell e Don Mitchell, quando estes falam da construção de um ambiente urbano mais justo e menos excludente. $\mathrm{O}$ direito à cidade é um meio de minimizar a reprodução das desigualdades sociais e do padrão excludente e concentrador de riqueza da urbanização. Este direito significa a prerrogativa de usufruir de um ambiente citadino harmônico com os princípios de sustentabilidade, democracia, equidade e justiça social.

O que se entende como direito à cidade é traduzido pelo artigo constitucional 182, quando este informa que a política de desenvolvimento urbano tem por objetivo ordenar o pleno desenvolvimento das funções sociais da cidade e garantir o bem-estar de seus habitantes. Para regulamentar tal dispositivo é promulgado o Estatuto da Cidade (Lei $\left.\mathrm{n}^{\mathrm{o}} 10.257 / 2001\right)$. 
O Estatuto da Cidade, em seu artigo $2^{\circ}$, elenca as diretrizes gerais que devem inspirar a formulação e execução da política urbana. Carvalho Filho (2013, p.30) agrupa tais diretrizes em cinco categorias, quais sejam: 1) diretrizes governamentais que estão relacionadas com a atuação direta do poder público como o planejamento do desenvolvimento das cidades e oferta de equipamentos urbanos; 2) diretrizes sociais, consideradas as que visam proporcionar algum tipo de benefício direto à coletividade ou que admitem a participação da comunidade no processo de urbanização com destaque ao direito às cidades sustentáveis e gestão democrática; 3) diretrizes econômico-financeiras, aquelas que dizem respeito aos recursos e investimentos alocados ou obtidos para o fim de desenvolvimento do processo de urbanização; 4) diretrizes jurídicas, caracterizadas pelas produção de normas referentes às cidades; 5) diretrizes relativas ao solo urbano correspondentes aos vários instrumentos destinados ao processo de uso e ocupação do solo urbano: ordenação e controle do uso do solo, visando impedir situações nocivas à coletividade, como usos incompatíveis, excessivos ou inadequados do solo, deterioração de áreas urbanizadas e poluição ambiental.

Dentre as diretrizes anteriormente mencionadas, merece destaque o direito às cidades sustentáveis, constante no inciso I do artigo $2^{\circ}$ do Estatuto. Tal inciso garante o direito às cidades sustentáveis, entendido como o direito à terra urbana, à moradia, ao saneamento ambiental, à infraestrutura urbana, ao transporte e aos serviços públicos, ao trabalho e ao lazer, para as presentes e futuras gerações. Tal direito se constituí como o direito fundamental das populações urbanas. A sustentabilidade das cidades está na compatibilidade entre o desenvolvimento da cidade, o bem-estar dos habitantes e a preservação ambiental. Um outro ponto de destaque é a ordenação e controle do uso do solo a fim de evitar a poluição e degradação ambiental. Uma das maiores preocupações da política urbana é a proteção ambiental, o que se justifica pelo fato de o meio ambiente retratar bem jurídico e direito transindividual difuso que tem suporte na própria Constituição Federal (artigo 225) (CARVALHO FILHO, 2013, pp.46-47)

Interessante notar também a projeção internacional do direito à cidade e o forte diálogo existente entre o processo de juridicização do direito à cidade no âmbito nacional e as discussões internacionais sobre o assunto. Nesse sentido, Nelson Saule Junior afirma que a experiência brasileira de buscar o reconhecimento institucional do direito à cidade a partir de uma ação política da defesa da implantação da plataforma da reforma urbana contribuiu para que fosse introduzido, gradativamente, nos fóruns internacionais urbanos, o direito à cidade, 
na pauta dos processos globais voltados a tratar dos assentamentos humanos (SAULE JÚNIOR, 2007, p.34).

Nesse processo de internacionalização, tem especial destaque a Carta Mundial do Direito à Cidade, que se traduz em um esforço importante de reunir diversas normas sobre direitos econômicos, sociais, culturais e ambientais. A Carta Mundial concebe este direito como um direito coletivo e indivisível que contempla a diversidade por meio de reconhecimento dos difusos e múltiplos interesses de todos os moradores da cidade, bem como representando a dinâmica relação entre pessoas e lugares. Enfim, o direito à cidade é entendido como usufruto equitativo da cidade dentro dos princípios da sustentabilidade, democracia, equidade e justiça social (art. I.2). O documento tem o potencial de servir como declaração de direitos que embasa reclames sociais e legitima ações coletivas organizadas sua elaboração envolveu diversos atores que, reunidos em fóruns mundiais se dispunham a promover cidades mais igualitárias, democráticas e sustentáveis (MORETTI, J; MORETTI, R, 2014, p. 64).

Esse histórico dá vida aos dois pilares do direito à cidade, quais sejam, gestão democrática e acesso equitativo a bens e direitos, tal como proposto no documento. Embasado no princípio da função socioambiental da propriedade, os termos da Carta Mundial pretendem reverter a predominância de valores econômicos e financeiros em detrimento da função social da cidade (OSORIO, 2006). A Carta pode ser uma referência para a elaboração de políticas públicas, inclusive de saneamento, visto que incorpora um artigo sobre direito à água, ao acesso e à administração dos serviços públicos domiciliares e urbanos (art. XII) no qual, como instrumento jurídico para a afirmação de direitos, assegura a todos os cidadãos o acesso permanente aos serviços de saneamento (água, esgotamento, coleta lixo) com tarifas acessíveis e serviços adequados, fortalecendo também a dimensão participativa com previsão de controle social permanente. No entanto, a implementação do direito à cidade é desafiada por um crescimento constante da informalidade que nega a uma parcela significativa da população a possibilidade de compartilhar os benefícios da urbanização. Assim, é importante refletir sobre os mecanismos de afirmação do direito a cidade, bem como sobre o papel do direito na promoção da informalidade e aprofundamento da segregação no tecido urbano (MORETTI, J; MORETTI, R, 2014, p. 65). 
O saneamento básico é designado como o conjunto de medidas que visam a garantir a preservação ambiental e manutenção de resíduos, através de serviços de abastecimento de água potável, esgotamento sanitário, drenagem, limpeza urbana e manejos de resíduos sólidos e de águas pluviais. Trata-se de serviços que podem ser prestados por empresas públicas ou, em regime de concessão, por empresas privadas, sendo esses serviços considerados essenciais (SARLET; FENSTERSEIFER, 2011, pp.117-118).

Embora o saneamento básico não esteja expressamente previsto na Constituição Federal como um direito, pode-se considerar que integra o rol de serviços públicos indispensáveis à efetivação dos direitos sociais. Segundo Sarlet e Fensterseifer (2011, p.117), o saneamento básico atua como o campo adequado ao combate da pobreza e da degradação do ambiente, de modo que a efetividade dos serviços de abastecimento de água e de esgotamento sanitário integra o rol dos direitos fundamentais sociais, como o direito à saúde, o direito ao ambiente, incluindo o direito à água, essencial a dignidade humana. O saneamento básico caracteriza-se como um direito e dever fundamental do indivíduo e da coletividade.

O saneamento básico foi elevado à categoria de direito fundamental pela própria Constituição Federal, quando estabelece no seu artigo 225 a proteção ao meio ambiente ecologicamente equilibrado, garante os direitos sociais à saúde e moradia digna e coloca a dignidade da pessoa humana como fundamento do Estado brasileiro.

Um outro fator que fortaleceu o saneamento básico como direito foi a promulgação da Lei Federal 11.445/2007 que prevê a universalização dos serviços de abastecimento de água e tratamento da rede de esgoto, além de estabelecer as regras básicas para o setor ao definir as competências do governo federal, estados e prefeituras.

Já no cenário internacional, a Assembleia Geral da ONU, em 2010, declarou o reconhecimento do direito à água potável e ao saneamento como um direito humano essencial para o pleno desfrute da vida e de todos os direitos humanos. Assim, o direito humano e fundamental à água potável e ao saneamento básico cumpre papel central não apenas para o resguardo do seu próprio âmbito de proteção e conteúdo, mas também para o gozo e o desfrute dos demais direitos humanos (liberais, sociais e ecológicos). Nesse sentido, a relação entre saneamento básico e proteção do ambiente resulta evidenciada, pois a ausência de redes de tratamento de esgoto implica não apenas em violação ao direito a água potável e ao saneamento básico do indivíduo e da comunidade como um todo, mas também reflete de 
forma direta no direito a viver em um ambiente sadio, equilibrado e seguro (SARLET; FENSTERSEIFER, 2011, pp.116-117).

Em relação à articulação entre a política urbana e a política de saneamento, contemplada expressamente pela Lei $\mathrm{n}^{\circ}$ 11.445/07 (art. 2º, VI), afirma Paulo Roberto Ferreira Motta

Ao operador do direito comprometido com a cidadania não escapará a realidade de que a interpretação dos ditames generosos da Lei ${ }^{\circ} 11.445 / 07$ somente se completará com o alcance total da universalidade do acesso aos serviços públicos de saneamento básico, vinculada a esforços interpretativos em conjunto com o Estatuto das Cidades (MOTTA, 2009, p. 244).

Enfim, a afirmação do direito à cidade passa pela afirmação do direito ao saneamento ambiental e pode-se dizer que as diretrizes nacionais do saneamento estão em plena harmonia com o direito à cidade. Se o direito à cidade for encarado pelo viés da participação, a Lei $\mathrm{n}^{\circ}$ 11.445/07 traz com bastante ênfase a preocupação com a ampliação do controle social e participação de órgãos colegiados nos processos decisórios, colegiados esses compostos por uma pluralidade de atores, inclusive usuários e representantes da sociedade civil. Essa é uma medida fundamental para uma gestão do saneamento com um olhar mais ampliado, incorporando também a dimensão social e fortalecendo a cidadania. Com um ouvido apurado e olhar respeitoso, a aproximação com o usuário e sociedade civil pode colaborar na afirmação da justiça socioambiental ((MORETTI, J; MORETTI, R, 2014, p. 70).

Já pelo aspecto do acesso a bens e serviços, vemos que um dos princípios norteadores do saneamento é a universalização (art. $2^{\circ}$, I, Lei n ${ }^{\circ} 11.445 / 07$ ). A ampla garantia do saneamento, com seus múltiplos componentes, certamente trará uma condição de vida melhor e mais sadia para todos os habitantes da cidade, mas especialmente para os grupos mais vulneráveis. A implementação de políticas de saneamento, portanto, é medida que atende os comandos constitucionais ligados à proteção do meio ambiente (art. 225, Constituição) e à tutela da ordem urbanística (art. 182, Constituição), além de ter importante repercussão na erradicação da pobreza e da marginalização e redução das desigualdades sociais (art. $3^{\circ}$, III, Constituição) e afirmação da dignidade da pessoa humana (art. $1^{\text {o }}$, I, Constituição), especialmente considerando-se a injustiça ambiental que caracteriza o acesso ao saneamento no Brasil. 
A fim de exemplificar tal injustiça ambiental, vale a menção ao estudo divulgado pelo Ministério das Cidades, Panorama do Saneamento Básico no Brasil, o qual indica que a população que possui renda domiciliar mensal per capita de até 1 salário mínimo representa, aproximadamente, $79,5 \%$ do déficit em afastamento de esgotos sanitários, que corresponde a cerca de 43 milhões de habitantes do Brasil. Já $61 \%$ da população com rendimento mensal domiciliar de 1/4 de salário mínimo não têm acesso a práticas de afastamento de excretas e esgotos sanitários considerados adequados (BRASIL, 2014, p.125).

\section{4) SANEAMENTO BÁSICO E A POLÍTICA URBANA: PANORAMA DO SANEAMENTO NO BRASIL}

Como foi visto acima o saneamento básico é um direito assegurado pela Constituição Federal e definido pela Lei $\mathrm{n}^{\mathrm{o}} 11.445 / 2007$ como o conjunto de serviços, infraestrutura e instalações operacionais de abastecimento de água, esgotamento sanitário, limpeza urbana, drenagem urbana, manejos de resíduos sólidos e de águas pluviais. Neste momento, o artigo se propõe a analisar os dois principais serviços: abastecimento de água e esgotamento sanitário.

Nos últimos anos, o Brasil verificou um avanço importante no saneamento, mas o país continua atrasado em termos internacionais. Tanto o acesso à água tratada quanto aos serviços de esgotamento sanitário estão aquém dos observados por nações com padrões de desenvolvimento econômico semelhante. Isso implica prejuízos à qualidade de vida da população e à economia do país.

Com base nos dados divulgados pelo Sistema Nacional de Informações sobre Saneamento (SNIS), o Instituto Trata Brasil elaborou o relatório Benefícios Econômicos e Sociais da Expansão do Saneamento no Brasil. Segundo esse relatório, em 2005, 81,7\% da população brasileira foi atendida com abastecimento de água em suas residências. Em 2015, essa proporção subiu para 83,3\% da população, ou seja, 26,4 milhões de habitantes passaram a ter acesso a esse serviço básico. No caso da coleta de esgoto, a cobertura chegou a apenas $53,3 \%$ dos habitantes em 2015, indicando um aumento de 10,8 pontos percentuais da população em dez anos. Nesse período, 32,5 milhões de pessoas passaram a ter acesoo ao serviço de coleta de esgoto. 
O avanço do saneamento também aparece nos dados de extensão das redes. Em 2005, a rede de distribuição de água tinha 40902 mil quilômetros, extensão que passou para 602,4 mil quilômetros em 2015. A taxa de crescimento foi de 3,9\% ao ano nesses dez anos. A rede de coleta de esgoto, por sua vez, passou de 158,4 quilômetros em 2005 para 284 mil quilômetros em 2005, apresentando um crescimento de 6,0\% ao ano.

\section{5) O IMPACTO DO SANEAMENTO BÁSICO NO DESENVOLVIMENTO URBANO}

É de se notar que o inciso VI, do artigo $2^{\circ}$, da lei Federal de Saneamento Básico, utilizou a palavra "articulação". O seu emprego, nesse contexto, indica a realização de contatos entre dois campos distintos. Tem um propósito de aproximação, no caso, dos serviços de saneamento básico com a política de desenvolvimento urbano. Por isso, "articulação" tem como sinônimo de "coordenação", ou seja, a concatenação das atividades promovidas em cada um desse âmbitos. Pretende-se, assim, a racionalização no conjunto de atividade e medidas tomadas para a prestação de serviços de saneamento básico e para a gestão da política urbana.

Pode-se afirmar a importância da articulação prescrita pela Lei de Saneamento, que pode colaborar decisivamente para o desenvolvimento urbano e para a própria organização dos serviços de saneamento. Isso porque uma articulação bem concebida tende a promover a racionalização do uso do solo urbano e uma distribuição mais equitativa dos serviços de saneamento na malha urbana.

Segundo o Ministério das Cidades, o desenvolvimento urbano pode ser descrito como a melhoria das condições materiais e subjetivas de vida nas cidades, com diminuição da desigualdade social e garantia da sustentabilidade ambiental, social e econômica. Os impactos causados pelo crescimento urbano afetam intimamente os serviços de saneamento básico. Quanto maior a população, mais intenso será o consumo de água, a geração de lixo e o acúmulo de poluição. Por isso, o grande desafio é alcançar a eficiência nas quatro vertentes do segmento, buscando a preservação ambiental e a promoção de um espaço urbano saudável.

$\mathrm{Na}$ prática, o investimento no saneamento municipal melhora a qualidade de vida da população e a proteção ao meio ambiente urbano, ao mesmo tempo em que gera emprego e renda para a cidade. Universalizar o saneamento condiciona resultados positivos a todos os Objetivos do Milênio elaborados pela Organização das Nações Unidas, em particular os que 
envolvem o meio ambiente, a redução da pobreza e da mortalidade infantil, a educação e a igualdade de gênero.

Entre 2005 e 2015, o investimento do setor de saneamento brasileiro foi, em média, de $\mathrm{R} \$ 9,264$ bilhões por ano. Estima-se que essas obras sustentaram 68,3 mil empregos diretos por ano na construção civil brasileira na média do período. Esses empregos pagaram $\mathrm{R} \$ 1,600$ bilhão de salários e remunerações e cerca de $\mathrm{R} \$ 777$ milhões de benefícios e contribuições trabalhistas (INSTITUTO TRATA BRASIL, 2017, p.15).

No mesmo período, os operadores de saneamento do Brasil obtiveram uma receita operacional total de R \$39,491 bilhões por ano. Desse faturamento, 64,4\% do total, foi devida a operações em tratamento e distribuição de água e 30,8\% do total foi devido às operações de coleta e tratamento de esgoto (INSTITUTO TRATA BRASIL, 2017, p.22).

Segundo dados do Sistema Nacional de Informações do Saneamento (SNIS), essas operações sustentaram 135,2 mil empregos diretos na média do período. Esses empregos implicaram despesas de $\mathrm{R} \$ 8,983$ bilhões com salários, remunerações, benefícios e contribuições trabalhistas. Desse total, $64,1 \%$ foi gasto diretamente com os funcionários e 35,9\%, com encargos e contribuições sociais (INSTITUTO TRATA BRASIL, 2017, p.23).

A falta de saneamento tem implicações imediatas sobre a saúde e a qualidade de vida da população que mora em áreas degradadas do ponto de vista ambiental. A falta de água tratada tem impacto direto sobre a saúde, principalmente dos mais novos e dos mais velhos, uma vez que aumenta a incidência de infecções gastrointestinais. A carência de serviços de coleta e de tratamento de esgoto, mesmo quando há o acesso à água tratada, é responsável por outra parte das infecções gastrointestinais e das doenças transmitidas por mosquitos e animais. Os problemas mais graves surgem nas beiras de rios e córregos contaminados ou em ruas onde passa esgoto a céu aberto - em valas, sarjetas, córregos ou rios e lagos. Mas está presente também na poluição dos reservatórios de água e nos mananciais cuja qualidade tem sido deteriorada ao longo dos anos. A exposição ambiental ao esgoto e a falta de água tratada provocam doenças que abalam a saúde de crianças, jovens e adultos (INSTITUTO TRATA BRASIL, 2017, p.25).

Com base em informações do Suplemento de Saúde da Pesquisa Nacional por Amostra de Domicílios de 2003 (IBGE, 2005) e da Pesquisa Nacional de Saúde de 2013 (IBGE, 2015), ambas realizadas pelo IBGE, buscou-se analisar em que medida a falta de acesso à água tratada e o déficit de esgotamento sanitário podem estar associados aos afastamentos das pessoas de suas atividades rotineiras em razão de infecções intestinais. Essa 
análise também buscou identificar o efeito da falta de saneamento sobre o número de dias de afastamento do trabalho ou do estudo. As pesquisas de saúde perguntaram a uma amostra representativa da população brasileira se houve afastamentos das atividades rotineira nas duas semanas anteriores à data da entrevista, qual o motivo dos afastamentos e por quantos dias os entrevistados estiveram afastados (INSTITUTO TRATA BRASIL, 2017, p.28).

Em 2013, 14,1 milhões de pessoas, o que equivalia a 7,1\% da população brasileira, indicou ter se afastado de suas atividades durante ao menos um dia nas duas semanas anteriores ao dia em que a entrevista foi realizada. Desse total, 576.213, ou 4,1\% dos afastamentos, foram causados por diarreias ou vômitos (infecções gastrointestinais presumíveis). Considerando as 52 semanas de um ano, pode-se extrapolar que houve 14,982 milhões de casos de afastamento por diarreia ou vômito em 2013. Esse número foi $26 \%$ menor que o verificado dez anos antes, em 2003, ano em que foram relatados 20,230 milhões de afastamentos por diarreia ou vômito. Isso aponta para uma redução expressiva, de quase 10\% ao ano no período, do número de casos relatados (INSTITUTO TRATA BRASIL, 2017, p.26).

\section{CONCLUSÃO}

O saneamento básico deve ser encarado como um dos elementos do direito à cidade, ainda mais em um contexto urbano em que se faz evidente um padrão de urbanização excludente e periférico, no qual o acesso à terra urbanizada e com infraestrutura é um desafio a pressionar a produção informal do território, com uma perversa associação entre pobreza, más condições de moradia e exposição a risco ambiental. Assim, a afirmação do direito à cidade passa pela afirmação do direito ao saneamento básico.

É preciso dizer que a diretriz de articulação da Lei de Saneamento possui um relevante papel na busca da qualidade de vida urbana. A prescrição normativa tem sua razão de ser, especialmente se for considerado os diversos problemas urbanos, ou seja, que se manifestam no espaço das cidades, guardam relação entre si, ditada pela natureza espacial que lhes é comum. Os problemas urbanos não surgem de maneira segmentada. Por isso, a percepção da realidade, na forma em que se apresenta, é essencial para compreender o quanto estra articulação é relevante para maior eficácia na solução dos problemas das cidades. 
A articulação entre a política urbana e a política de saneamento é possível em razão de um conjunto normativo que parte da Constituição Federal e que agora conta com normas legais e específicas de ambas as esferas. É importante perceber que a relação entre política urbana e os serviços de saneamento básico faz parte de um universo mais amplo, o da coordenação entre as políticas públicas. De fato, a política de desenvolvimento urbano integra-se ao objetivo de desenvolvimento nacional (art. $3^{\circ}$, inciso II c/c art.174, $\S 1^{\circ} \mathrm{c} / \mathrm{c}$ art. 182, caput e $\S 1^{\circ}$, da Constituição Federal), que consagra uma série de políticas setoriais. Dessa maneira, a necessidade de políticas intersetoriais conjugando política urbana e saneamento básico é essencial para a construção de cidades sustentáveis.

\section{REFERÊNCIAS}

AZEVEDO, Sérgio. Políticas públicas: discutindo modelos e alguns problemas de implementação. In. Políticas públicas e gestão local: programa interdisciplinar de capacitação de conselheiros municipais. Rio de Janeiro: Fase, 2003. pp. 38-44.

BARBIERI, Aline Fabiene; NOMA, Amélia Kimiko. A intersetorialidade nas políticas brasileiras de educação: a articulação setorial no Programa Saúde na Escola. Revista Educação Unisinos vol.21, n². São Leopoldo. 2017.pp. 137 -145.

BRASIL, Ministério das Cidades. Panorama do saneamento básico no Brasil - Análise situacional do déficit em saneamento básico. Vol. II. 2014.

CARVAlHO FILHO, José dos Santos. Comentários ao Estatuto da Cidade. 5. Ed. Ver., ampl. e atual. Atlas. São Paulo, 2013.

GARAJAU, N.I. 2013. Reflexões sobre a intersetorialidade como estratégia de gestão social. In: Simpósio Mineiro de Assistentes Sociais: Expressões Socioculturais da Crise do Capital e as Implicações para a Garantia dos Direitos Sociais e para o Serviço Social, 3, Belo Horizonte, 2013. Anais... Belo Horizonte, 1:1-12.

INOJOSA, Rose Marie. Sinergia em políticas e serviços públicos: desenvolvimento social com intersetorialidade. Cadernos Fundap, São Paulo, n. 22, 2001, p. 102-110.

JUNQUEIRA L.A.; INOJOSA, R. M.; KOMATSU, S. Descentralização e intersetorialidade: na gestão pública municipal no Brasil: a experiência de Fortaleza. Caracas: UNESCO/CLAD, 1998.

MORETTI, Julia Azevedo; MORETTI, Ricardo de Sousa. Saneamento como importante elemento do Direito à Cidade: ponderações sobre a política municipal de saneamento em São Paulo. Revista Direito, Estado e Sociedade ${ }^{\circ} 45$. Pontifícia Universidade Católica. Rio de Janeiro, jul/dez 2014. pp. 61-81. 
MOTTA, Paulo Roberto Ferreira. A universalização como princípio fundamental do regime jurídico do saneamento básico e do Estatuto das Cidades in Saneamento Básico Estudos e pareceres à luz da Lei 11.445/2007. PICININ, Juliana; FORTINI, Cristiana (Org.). Belo Horizonte: Fórum, 2009. pp. 237-246.

NASCIMENTO, Sueli do. Reflexões sobre a intersetorialidade entre as políticas públicas. Revista Serviço Social e Sociedade no 101. São Paulo. 2010, pp.95 -120.

OSORIO, Letícia. The World Charter on the Right to the City in International Public Debates - Urban Policies and the Right to the City. UNESCO (Org.) Paris: UNESCO, pp. 107-110, 2006.

SARLET, Ingo Wolfgang; FENSTERSEIFER, Tiago. Direito Constitucional Ambiental: estudos sobre a Constituição, os Direitos Fundamentais e a proteção do ambiente. São Paulo: Revista dos Tribunais, 2011.

SAULE JÚNIOR, Nelson. A relevância do Direito à Cidade na Construção de Cidades Justas, Democráticas e sustentáveis in Direito Urbanístico - Vias jurídica das Políticas Urbanas. SAULE JÚNIOR, Nelson (Org.). Porto Alegre: Sergio Antonio Fabris, p. 27-61, 2007.

SPOSATI, Aldaíza. Gestão pública intersetorial: sim ou não? Comentários de experiência. Serviço Social \& Sociedade, São Paulo, n. 85, mar. 2006, p. 133-141 